\title{
"Variations" in health
}

\author{
The costs of government timidity
}

From time to time researchers working on health inequalities listen with envy to stories from distant lands about open, all party talks organised by governments wanting to know what can be done to reduce inequalities in health. Last year the British government took its courage in both hands and unbarred the door to admit a small deputation of experts to talk about reducing the health divide. Political safety was ensured by limiting the discussion to what the NHS and the Department of Health could do. Poverty, housing, job insecurity, the inner cities, the rationing of health services, and other embarrassing problems were left outside, and the experts agreed to adopt their hosts' view of political correctness by referring to health "variations" rather than "inequalities."

Their report, published this week, is a welcome opening of negotiations. ${ }^{1}$ Although the evidence suggests that health services are not major contributors to health inequalities, the report's recommendations are worth while. As well as saying that health authorities should monitor health variations, target resources, ensure equal access, and evaluate interventions, the report also says a little (not enough) about the responsibilities of the NHS as the country's largest employer and-most crucially-emphasises the Department of Health's responsibility for informing the government of the impact of other aspects of policy on health.

As well as influencing the content of this report, however, the political constraints risk starting the discussion off on the wrong foot. There are cheap and expensive ways of tackling health inequalities, and the expensive ones are unlikely to be the best. What is expensive is to leave the underlying causes intact while establishing new services for those "at risk" in an attempt to repair continuing damage. Take, for example, the high rates of suicide among adolescents in Japan. They might have been tackled by identifying those at risk and then providing expensive counselling services in every school and college; but in fact suicides fell when students' paths through the educational system became more predictable, leaving less room for illusions and disappointments. The same can be said of job stress: instead of paying for counselling for employees, companies might find that changes in office practice could reduce absence due to sickness and increase productivity. ${ }^{2}$

The working group that produced this report drew heavily on a review of health service interventions intended to reduce health inequalities, commissioned by the working group from the Centre for Research and Dissemination. ${ }^{3}$ Ironically, most of the interventions involved people setting up local services to ameliorate the effects of national policies over which they had no control. Thus not only was the working group prevented from making recommendations to deal with causes of health inequalities lying outside the scope of health services but it drew heavily on policy models developed by people who could not hope to alter national policies.

Whether the health gain for a given preventive investment is higher among healthy rich people or unhealthy poor people will reflect the underlying policies. There is a paradoxical impression that health gains are most expensive where excess morbidity and mortality are greatest; this probably means that we are using the wrong policies. The solution is to be more radical and to tackle problems at their root. This is now essential. Despite Britain's comparatively low social expenditure ${ }^{4}$ there is little prospect that any government is likely to pay for a whole new layer of health services. Researchers will have to spend less time identifying high risk groups in need of new services and more time identifying ways of developing the social and economic institutions of our society so that the initial damage to health is prevented.

The confluence of poorer health and a range of other social problems associated with relative deprivation suggests that it should he possible to devise reforms that have multiple benefits. Indeed, in a broader context, new services may occasionally pay for themselves. For instance, the high/scope Perry randomised controlled trial of preschool education suggests that by the time children reach adulthood an initial investment can yield a sevenfold return by reducing crime rates and welfare dependency and improving educational performance and earnings. ${ }^{5}$ Clearly policy must be informed by a knowledge not only of health gains but of all the benefits likely to accrue from any proposed policy.

Getting the research focus right is an urgent priority. The Economic and Social Research Council's £4m programme of research on health variations is already under way, and the Department of Health is currently consulting on priorities for its own $£ 2.5 \mathrm{~m}$ research programme in this area. Ideally, as well as putting together the policy interests of a number of different sectors, research would evaluate interventions across a broad range of outcomes. If the government is to give itself a chance of making an appreciable impact on inequalities in health or any associated social problems it must overcome its fears and encourage more imaginative intersectoral approaches to policymaking. The 
new research programmes should form part of an integrated attempt to develop the productive resources of our society, to equip people to take a full role in its economic life, and to reduce the burden of deprivation.

RICHARD G WILKINSON Senior research fellow
1 Department of Health. Variations in health. What can the Department of Health and the NHS do? A report from the variations subgroup of the chief medical officer's Health of the Nation Working Group, Department of Health, 1995. London: DoH, 1995.

2 Karasek R, Theorell T. Healthy work: stress, productivity and the reconstruction of working life. New York: Basic Books, 1990

3 NHS Centre for Reviews and Dissemination. Review of the research on the effectiveness of health service interventions to reduce variations in health. York: University of York (in press). (Centre for Research and Dissemination report No 3.)

4 Hills J. The future of welfare. York: Joseph Rowntree Foundation, 1994.

5 Schweinhart LJ, Weikart DP. Success by empowerment: the high/scope Perry preschool study through age 27. Young Children 1993;49:54-8.

\section{Antenatal screening for carriers of hepatitis B virus}

\section{Britain needs a standardised nationwide universal screening programme}

Acute hepatitis B is becoming much less common in Britain now that blood and blood products are safe, health care staff are being vaccinated, infectious health care workers are being steered away from procedures that could transmit the virus, drug misusers have needle exchange schemes, and sexually active people have counselling and condoms. The current morbidity and mortality from hepatitis B mostly result from the chronic carrier state, ${ }^{1}$ and the prevention of persistent infection must be central to any strategy to control the virus and its effects.

The probability that infection with hepatitis B will become persistent decreases with the age at which infection occurs. Between $60 \%$ and $90 \%$ of babies born to the most infectious mothers (those positive for hepatitis $\mathrm{B}$ e antigen) become carriers if infected perinatally, whereas this happens to less than $10 \%$ of those people infected as adults. ${ }^{1-3}$ Perinatal infection can be prevented by prompt administration of immune prophylaxis at birth, ${ }^{45}$ and the prevention of perinatal infection in this way will have a substantial impact on the numbers of carriers in the future.

The Netherlands is one of Britain's closest neighbours in Europe, and its population includes immigrants from other parts of Europe and from parts of Asia, reflecting its colonial past. The two countries compare much better with each other than with the United States, with its financially polarised health care system. Britain should take advantage of two Dutch reports published in this week's journal ( $p$ 1197, p $1200^{7}$ ). Data have been gathered on antenatal screening for carriage of hepatitis B in nearly 100000 women over seven years in four centres. The results, therefore, present the overall position in the Netherlands with great accuracy.

Any programme to prevent perinatal infection must identify mothers who are carriers of hepatitis B virus. Within a largely European population the prevalence of infection can be expected to be relatively low, so some screening system is needed to identify the pregnancies at risk. Screening in late pregnancy proved not to be practical in those areas where half of the women were delivered at home under the care of midwives. The answer found was to incorporate screening for hepatitis B surface antigen with the antenatal screening tests for blood group and for syphilis routinely carried out at 14 weeks. This approach found 705 women who were positive for the surface antigen, of whom only two proved not to be long term carriers. The effectiveness of the screening programme was checked by looking for the results of screening tests at delivery and by cross checking the laboratory screening lists against birth registrations. Coverage in excess of $95 \%$ was reached by all centres by the end of the study. Of the 99706 women screened, $97 \cdot 3 \%$ were screened prenatally; only $2 \cdot 7 \%$ needed screening at delivery. The overall prevalence of carriage of hepatitis B surface antigen was $0.74 \%$, with higher rates in big cities-Rotterdam and Utrecht-and lower rates in rural areas, the suburbs, and communities with high socioeconomic indicators.

Unsurprisingly, the mothers presenting at delivery without antenatal care had a higher risk of being carriers of hepatitis B virus $(4.0 \%)$ and included more women in their first pregnancy. Sixty five per cent of the carrier women identified were European, and in a small study on women of Dutch origin in one centre a risk factor could be identified in only about half.

Many previous studies in countries with low endemicity, such as Britain and North America, have looked at selective versus universal antenatal screening. ${ }^{8-12}$ When a direct comparison has been made, selective screening failed to identify about half of the women whose babies were at risk..$^{8-10}$ Among the reasons for the failure of selective systems are the difficulty of discussing risk behaviour in a busy antenatal clinic, the possibility that women. with no risk factors might have been infected by a partner with a "risk history," and many infected women have no recognised risk factors. Selecting all non-European women would discriminate against the indigenous population-whose babies also need to be protected against this infection. As a result of the study in the Netherlands the Dutch national health authority has adopted as policy non-selective screening for hepatitis B infection with tests for blood group and syphilis early in pregnancy. Laboratories were requested to add an assay for hepatitis B surface antigen to their screening package for "a nominal sum."

In Britain the policy on antenatal screening for hepatitis B surface antigen acknowledges that selective screening fails to identify some carriers and that clinics should therefore consider offering screening to all patients. ${ }^{13}$ In a recent survey 32 districts out of 198 in England and Wales were found to be operating a universal screening policy, while 126 offered selective screening-not necessarily all on the same basisbut those districts offering universal screening were estimated to account for $27 \%$ of all the pregnancies (J Heptonstall, personal communication). Where universal testing was being offered the blood samples obtained at antenatal booking were tested by the regional blood transfusion centres, with confirmatory tests and tests for infectivity being referred to regional virology laboratories.

Previously, new large scale initiatives in public health have rarely happened without new funding, and finance may be one of the obstacles to the adoption of universal antenatal screening for hepatitis B in Britain. The cheaper the screening test the closer the cost of universal screening matches the cost of selective screening when the additional "interview" time is taken into account. ${ }^{14}$

In those parts of Britain where universal screening has been in place longest regional blood transfusion centres carry it out. 